\title{
ASPECT AND THE ENGLISH MODAL SYSTEM
}

Jack L. Wilson

\begin{abstract}
It is proposed that every English sentence contains not only time (past and non-past) but also aspect (perfective and imperfective). Whereas other languages may mark aspect formally, in English it is frequently a covert category and may give rise to ambiguities, especially in the written language. The interaction of aspect and time with the different modals is shown in an effort to describe the way the different modals are to be interpreted semantically.
\end{abstract}

Whereas other Indo-European languages, such as Spanish and Russian, morphologically mark perfective and imperfective aspect, English makes use of lexical or syntactic devices or leaves aspect as a covert, unmarked category. The result of this latter is a high degree of redundancy.

Russian verbs usually come in pairs, an imperfective form and a perfective form which is frequently derived from the imperfective form by any number of particles which permit a wealth of nuances in this language. In some cases an imperfective form may be accompanied by a different (non-derived) perfective form and in other cases a new imperfective form may be derived from a perfective from which had itself earlier been derived. The imperfective verb govorit' has within its scope a general meaning of "speak," "talk" or "say". The perfective form pogovorit' adds the idea of "for a short while." The perfective form skazat' is limited in meaning to "say" or "tell." The imperfective form pogovorivat' indicates "to be speaking for a short while." Thus we have the following sentences:

1. Nye ponyimayu, chto ty govorysh - I don't understand what you are saying.

2. Ya govoryu, chto eto stydno - I am saying that this is boring.
3. Ivan slyshkom mnogo govorit - John talks too much.

4. Pozvol'te bam skazat', chto vy postupili bestaktno - Let me tell you that you acted without tact.

5. Ya khochu govorit' o stranye moyey - I want to speak about my country.

6. Ya khochu s vami pogovorivat' - I want to talk to you for a minute.

Of special interest is the way the three languages, Russian, Spanish and English, deal with past and future time. In Spanish past time is marked morphologically as either perfective or imperfective and iteration is subsumed under this latter category, thus giving rise to a redundancy. In Russian past time is built around the corresponding perfective, simple imperfective or iterative verb form. English manifests a high degree of redundancy in past time, with a single form in which perfective, simple (non-progressive) imperfective and iteration are covert categories. This can be seen in the following sentences:

7. John drank beer.

That this sentence is three-ways redundant can be seen by the Russian translations: 
8. Ivan pil pivo. John (habitually) drank beer (i.e. John was a beer drinker. A stretch of time, not a point in time, is indicated).

9. Ivan vypil pivo. John drank beer (once, i.e. there was a single point in time involved).

10. Ivan vypival pivo, John (repeatedly) drank beer (i.e. there were several points in time involved).

Spanish has two forms corresponding to these three Russian sentences:

11. Juan tomaba cerveza. Same as 8 and 10 above.

12. Juan tomó cerveza. Same as 9 above.

The above sentences demonstrate that in English the difference between perfective and imperfective (both simple and iterative) aspect is covert, in Spanish that the difference between simple and iterative imperfective aspect is covert, and that in Russian the corresponding categories are overt.

Of special interest is the way Russian expresses the idea of simple future time: the perfective verb form is conjugated with present tense markers.

13. Ivan pit pivo. John drinks beer (habitually) or John is drinking beer (progressively, i.e. a point is advancing in time). The Russian sentence shows an ambiguity which is lacking in both Spanish and English.

14. Ivan vypit pivo. John will drink beer (once).

It might be mentioned here that Russian verbal conjugations apply only to two forms: past and present (or non-past).

Every Russian sentence must be marked formally both for time and for aspect and it is the interaction of these two parameters which accounts for what is interpreted as time in the future. What is of special relevancy is the fact that it is a present (or non-past) form combined with a perfective aspectual category which gives, basically, the idea of future. Other syntactic and morphological devices add a wealth of additional information, but this is the basic fact. As perfective aspect indicates the end (or beginning) of a state, a process or an action, it would seem to be the case that its combination with a present form can only indicate a projection towards a time in the future when that state, process or action can or will be terminated (or begun). If we use as parameters $[ \pm$ perfective] (where [- perfective]
= imperfective) and $[ \pm$ past], we would have the following possible readings:

$$
\text { Perfective aspect Past time }
$$

\section{5. p'yu}

"I drink, I am drinking." As the verb is not perfective and the time is not past, it is interpreted as an action (in this case) which takes place habitually or is taking place now.

16. pil

"I drank, was drinking, used to drink." Here the verb form is imperfective and the time is past. As an imperfective, duration and not completion of the action is focused on.

\section{7. vypil}

"I drank." Here emphasis is placed on termination of the action in the past.

18. vyp' yu

"I will drink." As emphasis is on termination (or beginning) of the action in a non-past time, that time can only be future.

Spanish functions exactly like Russian in the first three forms, but differs in the latter. Instead Spanish achieves the same result (a future meaning) by conjugating in the present a lexically perfective form ("haber") and then adding it as a suffix to the verb. Although the resulting future is of syntactic formation (beber + he $=$ beberé) both the perfective and nonpast elements are present.

Like Russian and Spanish English marks a formal difference between past and present but, unlike the other two languages, aspect is (morphologically) unmarked in English, giving rise to redundancy in the past. As for the future, English is like Spanish in the sense that it is formed syntactically instead of morphologically. But, unlike Spanish, aspect in the English future remains a covert category and can be brought to the fore only contextually, although in certain instances ambiguities may remain. In the English modal system this covert aspectual category plays an important role. 
The following discussion will be limited to what have sometimes been called the "true" modals. There are nine of these in English: will, would, shall, should, may, might, can, could and must. Just as Russian particles add meaning to perfective and imperfective verb forms, so these modals add meaning in their own right. When a modal is present in English, it is always accompanied by perfective/imperfective aspect as a covert category and by past/non-past time, also usually a covert category but because of other factors sometimes interpreted as an overt category.

Although gaps are to be expected, and are indeed found, these two parameters, aspect and time, should give rise to four general types of sentences involving the modals:

$\begin{array}{lcc} & \text { Perfective } & \text { Past } \\ \text { a. } & + & + \\ \text { b. } & - & + \\ \text { c. } & + & - \\ \text { d. } & - & -\end{array}$

Examples of the first type, however, are completely lacking in English. In their place we find sentences formed with the lexical perfective form "have," which adds the meaning of "relevancy," preceded by a modal whose form only occasionally could be interpreted as "past" (for example in the change from direct to indirect speech). Sentences which contain this perfective form relate two times one of which, of necessity, must precede the other. The meaning of a sentence of type a. should be that a process or an action ended at a certain point of time in the past. Notice that the termination or beginning of a state cannot be involved as this in itself would be a process. The modal chosen will add meaning on its own, and the use of the perfective marker "have" will indicate a past time which may be relevant to another past time, a past time relevant to the present or a relevant time which may be past, present or even future, but which is past with respect to another future.

I believe it is a mistake to consider that "would, should, might", "could" are the respective past forms of "will, shall, may" and "might." As indicated earlier, this might be true in the clange from indirect speech (or in changing a complex sentence from the present to the past as in "Adam thinks he will be going soon" : "Adam thought he would be going soon"). One of the various lexical meanings of "will" is "in the future," but this is incidental and even here it can be used in constructions interpreted as "past of a future". Rather, modal FORMS should all be considered as present (or non-past) and their semantic interpretation (sometimes as past, sometimes as present, sometimes as future) will depend on other factors. Examples of sentences of type a. are as follows:

19. When we get home tonight, the children will already have gone to bed.

In this sentence, "have" is a lexical perfective, "will" has a present form and adds the lexical meaning of "future time," and the combination "will have" gives the mental picture of a future event which is past with regards to another event which is still further in the future.

Certain of the modals have greater or lesser distributional possibilities. Sentences of type a. with "shall," for example, would appear somewhat stilted:

20. When I finish my degree, I hope I shall have learned a lot.

21. (Glowering housewife to cowering maid): By the time you get this room clean, you SHALL have swept under the bed.

Besides "will" and "shall" others of the modals can be used in conjunction with the relevancy "have" to form a mental picture of a past of a future, but in most cases the results seem somewhat artificial. This may be because it is part of human nature (or at least of our culture) to talk more about the past and the present than about the future. More frequently, with the exceptions of "will" and "shall", the use of a modal plus "have" is interpreted mentally as referring to events taking place in the past which are in some way relevant to the present. This time linkage may not be inmediately apparent, as in the following:

22 . The Big Bang must have taken place at least 20 billion years ago.

The relationship is seen in one of the meanings of "must": non-admissibility of the reverse possibility, i.e. the speaker (at the present time) does not accept that a certain event may have taken place at a later time in the past than that which he has indicated. Alternatively, we might refer to this use as "logical deduction." 
With the semantic restrictions noted above concerning "will" and "shall," all the modals may enter into constructions with "have" to manifest sentences of type a.i.e. that in each case one event (a process or an action) took place in the past.

In sentences of type b. (I- perfective, +pastD), two modals are found which do not require the addition of "have":

\section{Would}

23. That man would sit by the fire for hours on end.

24. When Edward was a child he would go to the movies every Saturday morning.

25 . The teacher wouldn't let his student repeat the exam.

\section{Could}

26. During the Middle Ages every educated person in Christian Europe could speak Latin.

27. Morgan's pirates could raze a town in a matter of hours.

28 . The pupil could recite the poem yesterday, but he can't today.

In sentence 26 the modal is followed by a stative construction, in sentences $23,24,25$ and 27 the immediately following construction in each case is non-stative, i.e. it represents an event. In sentence 23 the event is durative, and in sentences 24 and 27 it is iterative. "Would" in these sentences is equivalent to "used to" and "could" is equivalent to "knew how to" or "were able to." In 25 the modal manifests a definite refusal. The fact that type $b$. sentences are [- perfective] excludes their reporting single events. The semantic interpretation of type b. sentences is that of the description of a state, and because it is a state it is of necessity durative, in the past, or that of reporting a durative event, which in itself is the equivalent of a state, or iteration of events. English, like Spanish (but unlike Russian), treats iteration and duration in the same way: as [-perfective] ( $=[+$ imperfective]). For the other modals to enter into this category, "have" must be present.
As indicated earlier, type c. sentences ( $\mathrm{I}+$ perfective, - past] should mean that the state described or the event reported is projected into the future. For type $c$. sentences the statement made earlier about stative constructions must be revised as it seems clear that sentences of this type are closely related to sentences of type a. (in the sense that a. sentences would seem to correspond to the past of c. sentences, whereas b. sentences correspond to the past of $d$. sentences). Type a. sentences were limited to reporting single events in the past to the exclusion of states, a limitation which does not hold for the future. The reasoning is as follows. Referring to the past, [+perfective] refers to a terminal point in time and the termination of a state is a process. As regards the future, however, the terminal point may be that of a process, the result of which is a state. In the past states are considered as having duration. In the future they also have duration, but the state itself may have a beginning. If we say, for example,

29. The earth was round.

we do not focus either on beginning or ending, but rather on an extension of time in the past. On the other hand, if we say

30. The earth will be round what we are saying in effect, unless there is a greater context, is that

31. The earth will become round thus marking the beginning of a state. Sentence 29 , therefore, is [- perfective], but sentences 30 and 31 are [+perfective].

As we have seen, modals can be used in type a. construcions only through the addition of "have." Without this outside help, only two modals, "would" and "could" can be used in type b. constructions (with the exception noted above of indirect speech and of other complex sentences). All the modals can enter into type c. constructions. What these constructions will all have in common is the reporting of a single event, or numbered events, or focus on the beginning (or ending) of a state. Each modal adds its own meaning and establishes its own requirements and restrictions. Because of the similarity (or absolute identity) of forms in type c. and type $d$. sentences, possible ambiguities are to be expected, although the language has mechanisms to deal with them. As we sill see in dealing with type $d$. construtions, the spoken 
(intensity) accent (or stress) is frequently important in disambiguating sentences. Examples of type c. sentences are as follows:

\section{will}

32. "A man will come into your life," said the fortune-teller.

"Will" has the lexical meaning of "future time" on "prediction."

33. I will marry the woman of my dreams.

34. I WILL marry the woman I am engaged to.

Example 33, again, is a prediction, but 34 (stressed) is a promise.

35. If you will go with us, I will pay for the tickets.

In the first clause, the modal indicates willingness, and in the second a promise.

36. John WON'T come with us.

37. An Arab WON'T eat a porkchop.

The stressed negative modal indicates a refusal.

38 . Will you please open the window?

39 . Open the window, will you?

40. Open the window, won't you?

In these examplers the modal indicates acceptance or willingness and are different from the following:

41. You WILL open the window.

This latter expresses an order. All these sentences are [ + perfective, - past].

\section{Shall}

Spontaneous forms with "shall" are hard to find. There are, however, three types of examples involving the features [+perfective, -past], although the first is admittedly archaic and the third, at least in American English, is "bookish" or pedantic. etc.).

42. Thou shalt not kill (commit adultery,

Use of the modal here is intended to indicate a strong command; and, combined with "not" to indicate an absolute prohibition.

43. Shall I open the window? Please do. ("Yes, you will; "Yes, you shall.)

This seems to be the only use of "shall" which might be considered spontaneous and is equivalent to "Do you want me to...?" "Shall" here represents a request for agreement or an offer to do something for someone. Although the form of "shall" is [+present], aspect must be marked [+perfective] as a single event is involved ("opening the window") which, if it takes place, will do so in the future. The following forms, although sanctioned by centuries of textbook rule, seen stilted, or at least to have a literary flavor, in American English:

44. I (we) shall do as I (we) please.

45. You SHALL hand your homework in on time.

According to hallowed rule, "shall" substitutes for "will" in the first person singular or plural to indicate future time or prediction. The use of "shall" for the other persons indicates an order or the strong determination of the speaker that the premise of the predicate will be carried out. The same rule states that the use of "will" with the first person singular or plural represents a promise or the strong determination of the speaker, or speaker, to carry out this premise. When one of the most powerful of all English speakers of the twentieth century, General Douglas MacArthur, stated, on abandoning the Phillipines after the Japanese invasion,

46. I SHALL return,

he was criticized by linguistic purists for his misuse of the English language. His strong determination to return should have been expressed as

47. I WILL return.

\section{Would}

48. Bill Brown would buy anything he had the money for if he thought it was cheap.

"Would" manifests a hypothesis, what the speaker believes Bill would do, followed by a contingency relative to this hypothesis, introduced by "if"; therefore the sentence must be complex.

\section{Should}

49. We should leave now.

50. You should be a man. 
The use of the modal here expresses an opinion of the speaker concerning his expectation or an obligation he considers the person (or persons) spoken about has. The speaker thus introduces himself into the sentence. In 50 the meaning of "be" is "begin to behave like." "Begin" signals a point in time (in the future).

Rules concerning the use of "should" in expressions with hypothesis, which this speaker learned in school, give rise to the same objections noted earlier concerning the use of "shall" in c. type constructions (as, form example, in "If it stopped raining, I should have to take off my raincoat.")

The following example, however, is quite different:

51. If it should rain, we couldn't go out.

"Should" here is not part of a hypothesiscontingency construction. Rather, the meaning is "if it were the case that...", i.e. "should" translates what in some Indo-European languajes, in spanish for example, would be a subjunctive. Other examples where "should" translates the subjunctive are as follows:

52. He demanded that we should leave.

53. Should you insist on doing that, we would object strongly.

In 53 the first clause is equivalent to "if you (should) insist on doing that...."

54. You should try some of this delicious dessert.

To say that "should" here refers to an expectation of the speaker concerning what he considers an obligation of the person spoken about, or to, may seem strange, but in this case cultural patterns enter into play. In a classroom lecture Robin Lakoff compared sentences of this type with the Japanese honorific system of address. Compare the following:

55. John will go.

56. John should go.

57. John must go.

"Must" expresses more urgency (or obligation) than "should", which in turn in stronger than "will." As far as obligation is concerned, "will" is neutral. Compare this with a scene at a party. The social status of the hostess vis-à-vis those present may be determined by the choice of modal she uses to get them to partake of her dessert.
58. You WILL try some of this dessert.

This otherwise more neutral form can only be understood as the order of a superior to an inferior, perhaps a reluctant child.

59. You SHOULD try some of this dessert.

The hostess considers it desirable that someone of equal status (perhaps her husband) taste the dessert.

60 . You MUST try some of this delicious dessert.

The hostess here places herself so far below the illustrious guest that she has to convince him to try her dessert by practically obliging him to do so. On this scale, the stronger the modal used, the more polite is the resulting sentence.

\section{May}

61. May rain.

62. "You may have the car tonight," said the man to his teen-age son.

The modal in 61 expresses possibility and in 62 permission. Of interest here is the fact that in 61 the modal has a strong secondary accent (on a scale of 1 , strongest, to 4) whereas in 62 the accent is tertiary. A tertiary accent on the modal in 61 would indicate permission thus giving rise to an, at least, improbable sentence. In many instances involving the modals the degree of stress (that is, of the accent of intensity) will play an important role in preventing possible ambiguities as far as speech is concerned.

\section{Might}

63. Albert might be here sooner than expected.

Like "may" "might" indicates possibility.

\section{Can}

64. "You can start the engine whenever you're ready," said the instructor to his pupil.

Like "may," in 62, "can" here indicates permission.

65. At the meeting tonight, everyone can express his opinion.

The modal indicates "will be able to." 


\section{Could}

66. If I had wings, I could fly to the stars.

"Could" is like "would" in hypothesis-contingency constructions, adding the semantic feature of ability.

\section{Must}

67. We must be more careful next time.

"Must" expresses necessity, and is equivalent to "have to."

In sentences where the modal is marked as [-perfective, -past], i.e. in type d. constructions, the meaning expressed should include the concept of timelessness or indicate a situation (state or event) which holds true at the present moment.

\section{Will}

68. Boys will be boys.

69. That man will sit by the fireplace for hours on end.

70. A bull will ruin a china closet.

These sentences indicate a propensity or inevitability, not a prediction. In these three examples the predicate in each case manifests a durative activity ("be") in 68 , for example, is equivalent to "behave like"). In sentences like these the accent may be either strong or weak.

Compare the following sentences:

71. The sun will dry the clothes.

72. The sun will dry clothes.

In 71 the reference to "clothes" is specific, whereas in 72 the reference is generic. In 71 the time is future (I+perfective; -past $)$ whether or not the modal is accented. An unaccented modal in 72 , however, without further context gives rise to an ambiguity: the speaker may be making a prediction (I+perfective, -pastD) or he may be referring to a propensity of the sun (Iperfective, -past]), i.e.to a timeless characteristic.

73. The sun WILL dry clothes.

Here there is no ambiguity. The reference can only be to a propensity when the modal carries a strong accent.

74. The sun WILL dry.

75. Windows WILL stick.
76. A fire WILL burn.

77. People WILL die.

In each of these examples the predicate manifests a simple (non-activity) process. With strong stress the modal indicates a propensity, or inevitability, with weak stress a prediction.

78. A Frenchman WILL know French.

79. Babies WILL be small.

The predicate in these examples is stative and the modal must be stressed. An unstressed modal would indicate a prediction with unacceptable results. The concept expressed in these examples is of inevitability.

\section{Would}

80. Speaker A: Frank'll go with us. Speaker B: He WOULD.

81. Speaker A: Frank is with us. Speaker B: He WOULD be.

82. Frank WOULD want to come with us.

83. You WOULD say that.

None of these constructions with "would" are past, none are future. The modal conveys a general meaning of disapproval on the part of the speaker as regards a certain situation.

84. Would you please close the door? (*Yes, I would; *No, I wouldn't.)

Appropriate responses to 84 would be "Yes, of course," or, "No, l'ld rather not." The modal in this instance introduces a polite request and is thus marked as [+perfective]. Compare this with the following:

85 . What would you like?

86. I would like a cup of coffee.

87. I would like to know French.

88. I would like to speak French.

89. I would like to speak in French.

Sentence 85 is a polite equivalent to "What do you want?," therefore, [-perfective, -past]. Sentence 86 is a polite answer. Each of the following three sentences has two parts: the first consists of "I would like," and has the aspect-time features of 86; and, a second part introduced by an infinitive which may include differing features. In 87 , for example, "to know French" manifests a state, therefore, in the context of the sentence, the infinitive has the features [-perfective, -past]. (I find it interesting that in Spanish a sentence such as 87 would be ambiguous. This is due to the fact that in this language "saber" my be either $\amalg$ perfectivel, 
whereas in English it must always be [-perfective], i.e. in English "know" is always stative. The English correspondence to Spanish [+perfective] "saber" would be "learn.") Sentence 89 points to a future action, therefore the infinitive has the features [+perfective, -past]. Sentence 88 is ambiguous and, without greater context, may have the features of either 87 or 89 .

90 . What would you have me do?

This sentence is exactly like 89 and is the semantic equivalent of "What do you want me to do?" "Would (have)" would be marked as [-perfective, -past], "do" as [+perfective, -past].

91. Would you like a piece of cake?

92. Would you like to visit Spain?

93. Would you, by any chance, speak French?

In these sentences, "would...like" is analogous to "do...want" and "would...know" to "do...know." Similar to "would...like" in their behavior (and covert markings) are "would...rather" and "would...sooner".

\section{Shall}

No examples of sentences of type d. (I-perfective, -pastD are found in English. In a timeless sense of inevitability or propensity none of the following are possible English sentences:

94. *Boys shall be boys.

95. "A bull SHALL ruin a china closet.

96. "I SHALL sit by the fireplace for hours on end.

\section{Should}

97. You should speak French.

98. You SHOULD speak French.

As written, sentence 97 is ambiguous. "Speak French" may indicate an action ("do something") or a state ("be a French speaker"). In speaking, however, the ambiguity disappears: if the modal is weakly stressed, a future action is predicted; it the modal is strongly stressed, a present state is indicated. In this latter case, the meaning is of an expectation the speaker has concerning the person (or object) spoken about. In 98 the speaker expects the person spoken to be able to speak French, perhaps because this person spent many years in France.

99. Children should wash behind their ears.

The genericness of "children" indicates an expectation concerning an obligation which the speaker believes generally holds; therefore, the modal may carry weak stress. Compare this sentence with the following:

100. Those children should wash behind their ears.

The speaker here indicates his belief that certain specified children have an obligation to carry out a certain action. In 99 the modal is marked as [-perfective], in 100 as [+perfective]. We might label this use of the modal, in both cases, as "escapable obligation."

101. the fact that the Sultan of Brunei should be so rich is a disgrace to mankind.

102. He shouldn't be so rich.

103. If he should be poor, on the other hand, then I apologize.

104. Should you don that, we would have to object.

The first three sentences are [-perfective]. Sentence 102 expresses a condition which the speaker considers is advisable. In 101 and 103 the modal corresponds to a subjunctive. In 104 "should" corresponds to a subjunctive in the contingency of a hypothesis, and the whole clause is equivalent to "If you (should) do thaT...."

\section{Can}

105. That merchant can drive a hard bargain.

106. Most Paraguayans can speak Guarani.

The modal expresses ability. The predicate in 105 expresses a generic situation, and the predicate in 106 expresses a durative situation. In both cases the predicate is descriptive of the subject and not the reporting of an event. For further clarity, these sentences correspond to:

107. That merchant is a hard-bargain driver.

108. Most Paraguayans are Guarani speakers.

Another use of "can" is seen in the following examples:

109. That sign can't not mean something.

110. Costa Ricans can't not know Spanish.

Although the examples may seem a little 
strange, they are perfectly well formed and indicate non-admissibility of a supposition.

111. The guests can't be leaving so soon.

Here again the meaning is non-admissibility of a supposition. The use of "be + -ing" is important in insuring that the active (non-stative) predicate is understood as [-perfective].

112. Mr. Smith can use the company car any time he wishes.

113. Wars can, and do, break out for the most trivial reasons.

In 112 the modal indicates permission, and in 123 possibility. These sentences, which are [-perfective], are equivalent to:

114. Mr. Smith has permission to use the company car any time he wishers.

115. It is possible for wars to break out, and they do, for the most trivial reasons.

\section{Could}

116. Who could that be at the door? It COULD be Billy.

117. Mikhail Gorbachov COULD be the Soviet leader of the second half of this century.

118. Bill COULD be the owner of this house.

The speaker in these sentences indicates the possibility that a supposition in true. If the modal in each of these examples weren't stressed, the predicate would be understood as [+perfective] and the meaning of "be" would be "become." The question in 116 is the only exception: it may be stressed or unstressed.

\section{May}

119. Mr. Maloney MAY own this piece of property.

120. No driver may exceed the speed limit.

121. May you have a Merry Christimas.

122. May our political opponents fare badly in the next election.

The three uses of "may" [-perfective, -past] are illustrated above. In 119 the modal must be stressed to indicate "possibility." The unstressed modal in 120 indicates permission, and in 121 and 122 we find (again unstressed) the optative modal.

\section{Might}

123. Umberto Eco might have the answer to the Templar riddle.

124. That clown might just seem to be a fool; he certainly knows his trade.

125. We might have what you are looking for on the next floor.

This modal is the equivalent of "It is possible that...."

\section{Must}

126. The operating room must be kept clean at all times.

127. One must eat to live.

128. You must know my brother ken; you were in the same classes in the university.

129. You must not walk on the grass.

In 126 and 127 the modal indicates necessity or inescapable obligation, in 128 inference, conclusion or logical deduction. The negative modal in 129 indicates prohibition.

In all of the above discussion, what is important is not so much the uses of the modals but the fact that they help to corroborate the thesis that in every English declarative sentence there is an interaction of aspect (I \pm perfective $D$ and time $(I \pm$ pastD). In speaking, and writing, about English grammar, we are accustomed to considering time, but aspect has been neglected except where it is specifically manifested as an overt, lexical, category (especially "have -en" to manifest [+perfective] and "be -ing" to manifest [-perfectiveD. The fact remains, however, that every English sentence expresses this aspect, although to bring it to the surface (i.e. to consciousness) frequently contextual features are required. Whereas in the Slavic and Romance languages (of which Russian and Spanish, respectively, are examples) the overt marking of aspect attracts the attention of a native-English speaker, English frequently shows ambiguities which do not exist in these languages, or has recourse to contextual circumlocutions which these languages don't require. At bottom, however, English is no different from these other languages in its dependency on timeaspect which, indeed, may be a universal fact of language. 
